\title{
BIOLOGICAL DIFFERENCES BETWEEN SEA WATERS: EXPERIMENTS IN 1953
}

\author{
By Douglas P. Wilson, D.Sc. and F. A. J. Armstrong \\ The Plymouth Laboratory
}

(Text-fig. I)

The experiments during the 1953 season were arranged to investigate certain criticisms and suggestions made to us after publication of the earlier work (Wilson, I95I; Wilson \& Armstrong, I952), and there were included tests of our own devising intended to narrow the field within which must be made any search for an explanation of the observed biological differences between sea waters from different localities. We were again unable to obtain water from the Celtic Sea and once more, by kind co-operation of the Millport Marine Station, used water from the Firth of Clyde instead. Both the E I and Clyde waters were collected on the same day and the fertilizations of Echinus esculentus were made and the experiments started 4 days later, which was the minimum time possible after collection of the Clyde water. Every experiment included a control comparison of the two waters.

One of the more interesting investigations last year was the effect on the larvae of Echinus of water passed through active carbon. Unfortunately further investigation, as detailed below (p. 35I), showed that the sample of carbon used contained a significant amount of copper, and the results obtained may be therefore attributable to the presence of that metal. This was found by analysis of the carbon and checked by analysis of sea water passed through it and, later, by the addition of copper to sea water in a section of Exp. I below. Messrs Sutcliffe, Speakman and Co., on being informed of our observations, very kindly supplied a sample of active carbon substantially free from copper with which we were able to repeat last year's experiment with different results.

In a review (f. Conseil, Vol. I8, p. 249) of a paper by Loosanoff and others and also in private correspondence, Dr H. A. Cole pointed out that no attention has been paid to the possibility that differences between waters may be due to bacterial activity during the period between collection and use. He suggested that, to test this, water should be filtered free from bacteria at the time of collection. This we have endeavoured to do as recorded below.

That extracts from adult Echinus could supply substances needed by the developing larva was a possibility worth testing. Water in which larvae had decayed and presumably released materials into the water was filtered and tested. 
From time to time it has been suggested to us by various people that vitamin $B_{12}$ would be likely to benefit larvae developing in water to which it had been added. We are grateful to Dr A. P. Orr for informing us that at Millport improvement in fertilization of Echinus had been effected by the action of E.D.T.A. in sequestering heavy metals and for referring us to work by Tyler (1953). Tyler claims a significant increase in the life-span of sperm pretreated with versene (E.D.T.A.) - which he used amongst other sequestering agents-as well as an improvement of the fertilization reaction.

The stability to heat of the factor responsible for the differences between waters was tested by heating the waters at boiling-point and also by autoclaving.

Half a century ago Herbst (see list of papers in Needham, I93I) in a series of papers described the different effects obtained by rearing echinoderm larvae in artificial sea waters from which he omitted one normal constituent. We decided to observe the effect of rearing the larvae in an artificial sea water known to contain all normal inorganic constituents, because the factor we are seeking is most probably not one of these.

\section{Cleaning of Apparatus METHODS}

The methods used in the earlier experiments were followed. Glassware was cleaned with hot I: I sulphuric acid, and the filtering apparatus was sterilized in an autoclave and washed with boiled distilled water before use.

\section{Collection of Water}

Water from the International Hydrographic Station E I was taken from the sea surface with a wooden bucket and was strained through 200-mesh boltingsilk into a cleaned carboy. Clyde water was taken in the Largs channel near Millport, being dipped from the sea in a glass breffit and strained through 200-mesh bolting-silk into a carboy cleaned and dispatched from Plymouth.

\section{Collection of Bacteria-Free Water}

The most practicable method seemed to us to be one in which water was drawn through a bacteriological filter into a sterile bottle. The apparatus had to be portable and simple. The first arrangement tried was that shown in Fig. I A. After cleaning, the Winchester bottle was evacuated at a water pump, the rubber tube being disconnected. The tap was then closed, the tube and filter candle attached, and the whole arrangement was sterilized by heating in an autoclave at Io p.s.i. pressure for $30 \mathrm{~min}$. The stopcock was lubricated with a silicone grease which did not run when heated. To collect water the filter candle was immersed in a bucket of sea water and the tap opened to allow the water to be drawn through the candle into the bottle. On test, the apparatus held a vacuum for a week in the laboratory and the sterilization was 
satisfactory. In use, however, the stopcocks leaked, possibly because of vibration in transit, and the arrangement of a sealed breakable glass tube shown in Fig. I B was substituted. Although this avoided leakage, the samples were still not sterile. We think it likely that the Berkefeld filter candles were not of

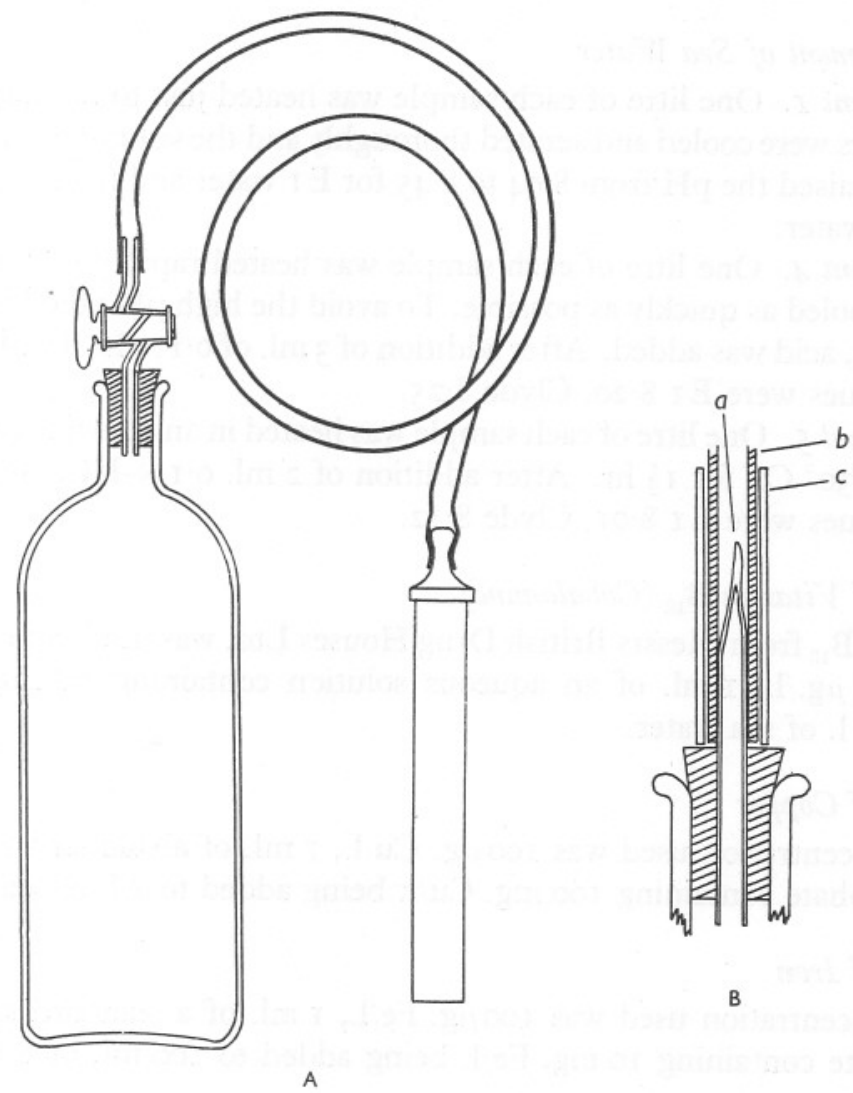

Fig. I. A, Winchester bottle with filter candle attached for collecting filtered water. B, sealed tube arrangement to replace stopcock: (a) glass tube sealed after evacuation of bottle; (b) rubber tubing; (c) loosely fitting thick glass sleeve to protect tip of A. The apparatus is evacuated, sealed and assembled, and then sterilized. In use the sleeve $c$ is slid up the rubber tube and the tip of $a$ broken off inside $b$.

a sufficiently fine porosity. On one occasion, however, a sample was obtained which was sterile by our tests, and the experiments show that no obvious harmful effects are caused by the rubber or ceramic of the filter apparatus.

\section{Sterility Testing}

We are indebted to Dr C. H. Jellard, Public Health Laboratory Service, for his help and interest in this part of the work. Dr Jellard himself carried out most of the inoculations. On one or two occasions one of us (F.A.J.A.) did them. 
The media used were: (i) peptone sea water, (ii) peptone sea-water agar, (iii) casein sea-water agar, as described by Spencer (I952).

Tubes and Petri dishes were incubated at $22^{\circ} \mathrm{C}$. The sample considered satisfactorily sterile showed no bacterial growth after 3 weeks.

\section{Heat Treatment of Sea Water}

Experiment I. One litre of each sample was heated just to boiling for I hr. The samples were cooled and aerated thoroughly and the volume adjusted. The treatment raised the $\mathrm{pH}$ from 8.04 to 8.45 for $\mathrm{E}$ I water and from 7.99 to 8.48 for Clyde water.

Experiment 4. One litre of each sample was heated rapidly just to boiling, and then cooled as quickly as possible. To avoid the high $\mathrm{pH}$ noted in the first experiment, acid was added. After addition of $3 \mathrm{ml}$. of $0 . \mathrm{I} \mathrm{N}-\mathrm{HCl}$ and aeration, the $\mathrm{pH}$ values were $\mathrm{E}_{\mathrm{I}} 8 \cdot 20$, Clyde $8 \cdot 25$.

Experiment 5. One litre of each sample was heated in an autoclave at 25 p.s.i. pressure $\left(130^{\circ} \mathrm{C}\right.$.) for $\mathrm{I} \frac{1}{2} \mathrm{hr}$. After addition of $2 \mathrm{ml}$. $0 \cdot \mathrm{I} \mathrm{N}-\mathrm{HCl}$ and aeration the $\mathrm{pH}$ values were $\mathrm{E}_{\mathrm{I}} 8 \cdot 0 \mathrm{I}$, Clyde 8. I2.

\section{Addition of Vitamin $\mathrm{B}_{12}$ (Cobalamine)}

Vitamin $B_{12}$ from Messrs British Drug Houses Ltd. was used in a concentration of $\mathrm{I} \cdot \mathrm{I} \mu \mathrm{g}$./1., I ml. of an aqueous solution containing $\mathrm{I} \cdot \mathrm{I} \mathrm{mg}$./1. being added to $I$ l. of sea water.

\section{Addition of Copper}

The concentration used was $100 \mu \mathrm{g}$. Cu/l., I ml. of a standard solution of cupric sulphate containing $\mathrm{IOO} \mathrm{mg}$. $\mathrm{Cu} / \mathrm{l}$. being added to $\mathrm{I} 1$. of sea water.

\section{Addition of Iron}

The concentration used was $100 \mu \mathrm{g}$. Fe/1., I ml. of a standard solution of ferric citrate containing Io $\mathrm{mg}$. Fe/l. being added to $\mathrm{IOO} \mathrm{ml}$. of artificial sea water.

\section{Physiological Fluids}

A mixture of equal parts of coelomic fluids from male and female animals was used. Ovaries and testes were separately squeezed between glass plates, and the expressed liquids diluted with equal volumes of water. These fluids were filtered just before use, first on Whatman No. 4I (loose texture) filterpapers, and then on 'Gradocol' membranes, A.P.D. $0 \cdot 49 \mu$.

Water in which Larvae had Died and Decayed

This was from the beaker of E I water in Exp. I. After filtration on No. 4I paper and on a membrane it had a strong fishy but not unpleasant smell. It was well aerated before use. 


\section{Carbon Extracts}

After the 1952 experiments an attempt was made to identify the material obtained by acetone extraction of active carbon through which sea water had been passed. Copper as cupric chloride was found, in an amount too large to have come from the sea water. On examining the carbon, it was found to contain some I 500 p.p.m. of copper, in a form which was insoluble in acetone, but which became partly soluble after the carbon had been wetted with sea water. Moreover, on passing sea water through a column of the carbon, the copper content of the water increased from $6 \mu \mathrm{g}$. $/ 1$. (a normal value) to $60 \mu \mathrm{g}$. 1 . We consulted Messrs Sutcliffe, Speakman and Co., who very kindly supplied a sample of their carbon no. 3I5. On analysis it showed only a trace of copper, and no increase of the copper content was found when sea water was passed through this carbon.

This carbon was used to repeat the 1952 extraction experiments. Extracts of similar appearance were obtained. Copper was not detected in them.

\section{Artificial Sea Water}

The salts listed in the formula of Lyman \& Fleming (I940) for the hypothetical combination of ions in sea water were used. After aeration the $\mathrm{pH}$ was $8 \cdot 02$.

\section{Ethylene Diamine Tetra-acetic Acid}

The disodium dihydrate (Versene, Trilon B, Sequestrine, SETate, etc.) referred to here as E.D.T.A. was used as an approximately O.IM solution $(37 \cdot 2 \mathrm{~g} . / 1$.). Addition of $\mathrm{ro} \mathrm{ml}$. of this solution to I 1 . of sea water gave a concentration of approximately $0.00 \mathrm{I} \mathrm{M}$ or $370 \mathrm{mg}$. $/ 1$., and decreased the $\mathrm{pH}$ to between 5 and 6 . After addition of $18 \mathrm{ml}$. $0 . \mathrm{I} \mathrm{N}-\mathrm{NaOH}$ and thorough aeration the $\mathrm{pH}$ values were, in Exp. 4, E I 8.I2, Clyde 8.I7.

In Exp. 5, the procedure was altered slightly to minimize salinity changes. The O.I M E.D.T.A. solution was made up in artificial sea water, which was then adjusted to $\mathrm{pH} 8.66$ by adding sodium hydroxide. Io $\mathrm{ml}$. of this solution were added to I 1 . samples of the various sea waters, giving the same concentration (O.0OI M) of E.D.T.A. as in Exp. 4. Only $3 \mathrm{ml}$. of O. I N-NaOH were then needed to adjust the $\mathrm{pH}$ to suitable values. These were E I 8.07, Clyde 8.06, artificial sea water 8.14.

\section{Antibiotics}

Penicillin G (Benzyl Penicillin B.P.c.) Glaxo, and Streptomycin (calcium chloride) Glaxo were used, one mega-unit of each being dissolved in $5 \mathrm{ml}$. of distilled water. Small volumes of this solution were measured with a microburette into roo $\mathrm{ml}$. portions of Clyde water to give concentrations of IoO, 300 and 500 units $/ \mathrm{ml}$. 


\section{Fertilizations}

These were always made in a mixture of equal parts of Berkefeld filtered Clyde and EI waters, one male and one female being used, both carefully selected from a number of recently trawled sea urchins (Echinus esculentus L.).

After fertilization the eggs were immediately divided equally between two beakers, and each portion washed six times with one of the two waters. Eggs were distributed equally among the experimental dishes by the dipper method already described (Wilson, I95I, p. 5).

\section{EXPERIMENTAL RESULTS}

In every experiment at least four and often five dishes of each kind of water were tested. It should be emphasized that, unless noted to the contrary, larvae in all the dishes comprising a set of one kind of water were identical one with another. This uniformity within a set was very striking, and it was most unusual for any variation to appear before the fifth or sixth day. When differences between individual dishes within a set began to be noticeable the experiment was ended. This rarely happened before the larvae were obviously dying off.

\section{Experiment $I$}

EI water collected I6. iii. 53. Ship: R.V. Sabella with F.A.J.A. Salinity, 35.34; $\mathrm{pH} 8.04$; temperature at time of collection, $8.5^{\circ} \mathrm{C}$.

Clyde water collected I6. iii. 53. Small boat with Mr E. Latham. Salinity, 33.30; $\mathrm{pH} 7.99$; temperature at time of collection, $7 \cdot \mathrm{I}^{\circ} \mathrm{C}$.

The sea-urchins were trawled on I9 March I953 and kept under circulation until the fertilization was made on the following day. Out of about twenty sea-urchins opened none had completed spawning and only two were partially spent. A good fertilization was obtained from one ripe male and one ripe female, although a small percentage of the ova did not fertilize.

The following waters were tested. Each set comprised five dishes.

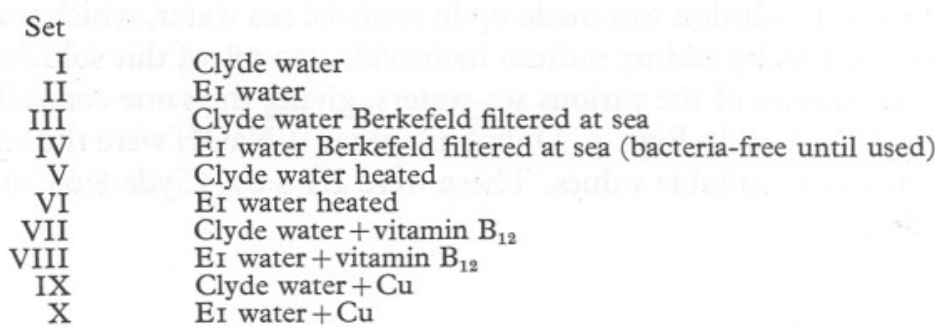

The larvae did better in the Clyde water (Set I) than in the E I water (Set II), but the difference was small compared with the more striking differences obtained in previous years. Nevertheless, it was clear that in the E I water there were more abnormal and stunted larvae than in the Clyde water and that the best plutei in the latter were more finely developed than 
the best in the E I water. When 2 days old the larvae in the Clyde water swam a little more strongly than those in the E I water, but there was never at any time a marked concentration up at the surface such as had often occurred in the better waters of previous experiments. On the sixth day (5-day-old larvae), when the larvae in all sets were dying, those in the E I water survived for a few hours in slightly better condition than those in the Clyde water.

It is worth mentioning that the two beakers, into which the eggs were divided after fertilization, had been kept as a check on the dishes. The concentration of larvae in these beakers was very much greater than in the dishes, and the difference between the two waters was here more marked. In the Clyde water the larvae swam more strongly and survived longer than those in the E I water.

Of the waters filtered through Berkefeld candles at sea (Sets III and IV) only that from EI proved to be bacteria-free when tested just before use. The Clyde water similarly filtered, and the waters in the carboys (which after filtration supplied Sets I and II) gave heavy bacterial growths on the test plates. The larvae in the EI water which had been bacteria-free between collection and use (Set IV) were no different from those in the other E I water (Set II) and were inferior to those in the Clyde waters. The larvae in the Clyde water filtered at sea (Set III) were no different from those in the control Set I and were, of course, better than those in both the E I waters (Sets II and IV). Incidentally the water in Set III had a thin oily film, derived presumably from the rubber connexions of the apparatus.

The Clyde water which was heated (Set V) was barely inferior as a rearing medium to that which had not been so heated, but the E I water after heating (Set VI) produced decidedly poorer larvae than did the unheated E I water.

The addition of vitamin $\mathrm{B}_{12}$ to the waters (Sets VII and VIII) made no difference whatever to the appearance of the larvae.

The water with copper proved to be poisonous; in the E I water (Set IX) most deaths took place during early cleavage, but in the Clyde water (Set X) mainly during the blastula stage.

\section{Experiment 2}

Particulars of E I and Clyde water as for Exp. I.

Fertilization made 27 March 1953 from sea-urchins trawled the previous day. Of the twenty opened only one or two were partially spent. About $100 \%$ of the ova fertilized, but nearly half cleaved irregularly and gave misshapen blastulae.

The following waters were tested. Each set comprised three dishes.

$$
\begin{aligned}
\text { Set } & \\
\text { I } & \text { Clyde water } \\
\text { II } & \text { EI water } \\
\text { III } & \text { EI water + filtered coelomic fluid from an adult Echinus } \\
\text { IV } & \text { EI water + filtered ovary juice from an adult Echinus } \\
\text { V } & \text { EI water + filtered testis juice from an adult Echinus } \\
\text { VI } & 75 \text { ml. EI water }+25 \text { ml. filtered EI water from Set IV } \\
& \text { of Exp. I after death and decay of the larvae }
\end{aligned}
$$


In the Clyde water (Set I) the larvae did a little better at first than in the E I water, but by the fifth day they were a little better in the EI water, repeating more or less the result in Exp. I. Again the beakers showed the most marked difference, the Clyde water giving the most vigorous larvae and the longest survival.

In all instances the additions (Sets III-VI) had slightly unfavourable effects on the development of the larvae, and each kind of addition had an effect a little different from any of the others. It is possible that the experiment was to some extent adversely affected by the large proportion of eggs in all dishes which failed to develop properly and died and decayed early.

\section{Experiment 3}

$E_{I}$ water collected I3. iv. 53. Ship: R.V. Sabella with F.A.J.A. Salinity, 35.30; temperature at time of collection, $8.7^{\circ} \mathrm{C}$.

Clyde water collected I3. iv. 53. Small boat with Mr N. Thomson. Salinity, 33.30.

In addition to the usual carboys of water strained through bolting-silk one Winchester of water filtered through a Berkefeld candle (see p. 348) was obtained from each locality. Unfortunately the glass stopper of the Clyde Winchester was broken on the journey back to Plymouth and half the water leaked away through a packing of sterilized cotton-wool. The water remaining in the Winchester from the Clyde proved to be heavily contaminated with bacteria, as did indeed also that from EI. These waters therefore can only be regarded as having been more efficiently freed from the larger plankton organisms at the time of collection than were the waters in the carboys.

The sea-urchins were trawled on I6 April and kept under circulation until a fertilization was made the following day. The following waters were tested. Each set comprised five dishes.

$\begin{aligned} \text { Set } & \\ \text { I } & \text { Clyde water } \\ \text { II } & \text { EI water } \\ \text { III } & \text { Clyde water filtered when collected } \\ \text { IV } & \text { EI water filtered when collected } \\ \text { V } & \text { Clyde water + Clyde extracts } \\ \text { VI } & \text { Clyde water + EI extracts } \\ \text { VII } & \text { Clyde water + blank extract } \\ \text { VIII } & \text { Clyde water through carbon } \\ \text { IX } & \text { EI water+Clyde extract } \\ \text { X } & \text { EI water+EI +extract } \\ \text { XI } & \text { EI water + blank extract } \\ \text { XII } & \text { EI water through carbon }\end{aligned}$

Apart from Sets III and IV the experiment was a repetition of Exp. III of 1952 (Wilson \& Armstrong, I952, pp. 344-7) in which an attempt had been made to extract a growth factor. As already explained (p. 35I) the active carbon 
used for this purpose was later discovered to contain a significant proportion of copper, which, while not appearing in the control blank extracts, affected the sea water passed through it and rendered certain conclusions invalid. In the present experiment an active carbon free from copper was used.

Throughout this experiment very little difference was discernible between the control Clyde and E I waters, Sets I and II, but the Clyde water had slightly better plutei until the fourth day, after which the plutei in the E I water were in a very slightly better condition. Some larvae in all dishes were dead on the fifth day and by the sixth day conditions generally were bad and the experiment was ended. At no time in either water were the plutei as well formed or as vigorously swimming as those in most previous experiments. It is not possible to be sure whether this was due to the condition of the waters or to unripeness of the eggs or sperm. About $100 \%$ of the eggs fertilized but a smali proportion cleaved irregularly.

In the water collected through Berkefeld filters that from the Clyde (Set III) had a slightly milky appearance, but nevertheless produced larvae almost as good as those in the Clyde water control (Set I). The larvae in the E I water filtered when collected (Set IV) were indistinguishable from those in the E I control (Set II).

As in the similar experiment the previous year the carbon extracts (Sets V, VI, IX and X) proved poisonous, while the blank extracts (Sets VII and XI) made very little difference to the waters to which they were added, the larvae in these dishes being very little inferior to those in the controls (Sets I and II). The important deviation from the results of 1952 is that the larvae in the waters which had passed the active carbon (Sets VIII and XII) were indistinguishable from those in the controls (Sets I and II), whereas in 1952 they were mainly abnormally formed and most of them died early. The I952 result must now be attributed to the presence of a toxic amount of copper, derived from the carbon, in the waters which had been passed through it.

\section{Experiment 4}

EI water collected 27. iv. 53. Ship: M.F.V. Sula with F.A.J.A. Salinity, 35.I7; $\mathrm{pH} 8.06$; temperature at time of collection, $9 \cdot 2^{\circ} \mathrm{C}$.

Clyde water collected 27. iv. 53. Small boat with Mr E. Latham. Salinity, 34.01; $\mathrm{pH} 8 \cdot 35$.

Two Winchesters of water filtered through Berkefeld candles were taken at each locality.

The sea-urchins were trawled on I May and the fertilization was made on the same day. On this date less than a quarter of the urchins opened had shed their genital products. In comparison with previous years this indicated a late spawning season. 
The following waters were tested. Each set comprised four dishes.

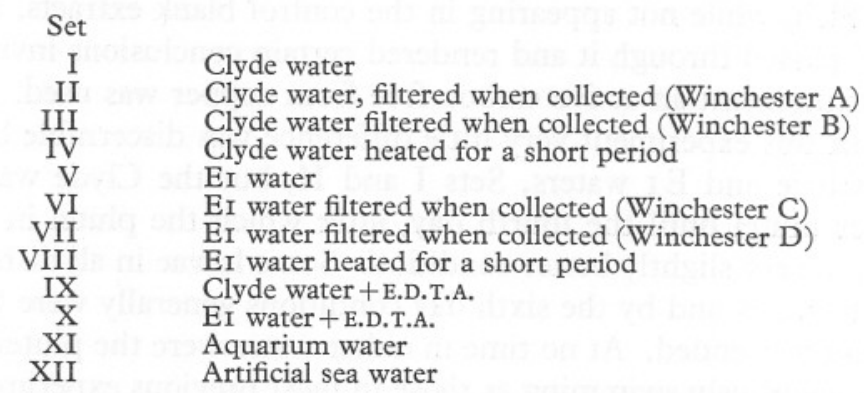

The experiment was originally planned to contain sets of Clyde and E I waters after heating in an autoclave for comparison with the same waters heated for a short period. Unfortunately the samples were accidentally spoilt during preparation and could not be used.

Throughout the 4 days' duration of the experiment (the larvae were everywhere dying when 5 days old) there was little to choose between larvae in the Clyde and E I controls (Sets I and V). Blastulae in the Clyde water swam up a little in advance of those in the E I water. At an age of 3 days there were more slightly abnormal larvae in the E I water than in the Clyde. The difference was just sufficiently marked for an independent observer to distinguish between them after a careful comparison. Thus the two waters, so far as their effects on the larvae were concerned, were almost identical. Although almost I00 \% of the eggs developed with very few abnormalities the larvae never showed any concentration near the surface as is usual with good cultures in good water. The room temperature rose slowly from 15.2 to $19.0^{\circ} \mathrm{C}$. during the experiment; for the first 2 or 3 days when surface concentrations normally take place it was not unduly high. In view of past experience the temperature is not regarded as having induced weakness in the larvae, in fact they swam most strongly when 3 days old at a temperature of $18^{\circ} \mathrm{C}$. The lack of vigour must therefore be due either to eggs or to sperm in poor condition, or to the condition of the waters. As the fertilization appeared initially to be good (well-raised fertilization membranes, even cleavage of almost all the eggs) it is reasonable to suspect that neither water was a perfect medium for the development of Echinus.

All the waters filtered at the time of collection (Sets II, III, VI and VII) gave heavy bacterial counts and the larvae reared in them differed in no way from those in the controls (Sets I and V), except Set VI where all larvae were always in poor condition with many dying at an early age. The reason for this has not been discovered, but it is thought that this water must in some way have become contaminated. The Berkefeld filter candle used was observed to have a dark stain, which while defying analysis may have been due to some toxic substance. Heating the waters for a short period (Sets IV and VIII) 
made no difference to the Clyde water but it very slightly worsened the E I water.

The addition of E.D.T.A. (Sets IX and X) did not improve either water; in fact the plutei showed slight abnormalities compared with those in the controls (Sets I and V).

The plutei in the aquarium water (Set XI) were always structurally inferior, with shorter arms, to those in the controls (Sets I and V) but they swam higher in the water and on the last day had fewer arm rods protruding from the shrinking flesh.

The plutei in the artificial sea water (Set XII) were decidedly small and stunted, but in the final stages did not degenerate as quickly as those in the Clyde and EI waters.

\section{Experiment 5}

EI water collected II. v. 53. Ship: R.V. Sabella, with F.A. J.A. Salinity, 35. I6; $\mathrm{pH} 8.08$; temperature at time of collection, $10.50^{\circ} \mathrm{C}$.

Clyde water collected II. v. 53. Small boat with Mr E. Latham. Salinity, 33.28; $\mathrm{pH} 8.07$.

The sea-urchins were trawled on I2 May, and kept under circulation until a fertilization was made on the following day. It was found that the majority had spawned or were partially spent. A good fertilization with almost $100 \%$ normal cleavage was obtained.

The following waters were tested. Each comprised a set of four dishes.

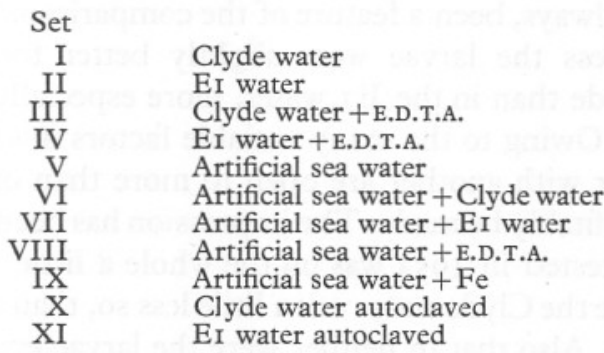

The eggs for Sets V-IX were washed in artificial sea water before being placed in the dishes.

In addition to the above some tests with penicillin and streptomycin were made, each in strengths of 100,300 and 1000 units $/ \mathrm{ml}$.

There was again very little difference between the controls, Sets I and II. For the first 2 or 3 days larvae in the Clyde water swam a little more strongly than in the E I water, and in both were more strongly swimming than in the similar waters of Exp. 4, though again neither showed the marked concentration at the surface which had been a feature of the best cultures in previous years. Later there was no difference in swimming vigour to be observed. Structurally there was no difference to be observed between the two sets of larvae throughout the experiment. 
The addition of E.D.T.A. made very little difference. When 2 days old the larvae in the waters with E.D.T.A. (Sets III and IV) swam a little more strongly than in the controls, but later they were not quite as vigorous and structurally became a little inferior to the larvae in the same waters without the sequestering agent.

Larvae in the artificial sea water (Set V) were a little inferior in swimming vigour and in structure to the larvae in the natural sea waters (Sets I-IV). They were better in the mixtures (Sets VI and VII), the mixture with Clyde water being slightly the better. The larvae were a little better in the artificial water to which E.D.T.A. had been added (Set VIII) except on the last day when they were worse. The addition of Fe (Set IX) to the artificial sea water made little or no difference to the larvae.

The larvae in the autoclaved Clyde and EI waters (Sets X and XI) were inferior structurally to those in the controls though for a short time they swam a little more vigorously.

The antibiotics had little or no effect on the larvae.

None of the differences throughout this experiment was anything more than slight.

\section{Discussion}

Throughout the 1953 experiments the two sorts of water were closely similar in their effect on the larvae and they never showed as marked a difference as had often, but not always, been a feature of the comparisons made in previous years. None the less the larvae were slightly better formed and a little healthier in the Clyde than in the E I water, more especially during the early part of the season. Owing to the many variable factors involved, direct comparisons of one year with another are open to more than one interpretation, and cannot very profitably be made. The impression has been gained, however, that the EI water tested in 1953 was on the whole a little more suitable for Echinus larvae, while the Clyde water was a little less so, than on most occasions when used in I952. Also that in neither were the larvae ever as well formed, or as vigorously swimming, as on the best occasions in earliest years. Their condition was always not very dissimilar from that recorded of the larvae in Exp. III of 1952 (Wilson \& Armstrong, I952, p. 344) where there was also little to choose between the two waters.

We are indebted to Dr Sheina M. Marshall for the information that a townet haul made in the Clyde in mid-April I953 contained forty-seven Sagitta elegans and thirteen Sagitta too young for certain identification. Mr P. G. Corbin informs us that the standard $\frac{1}{2}$ hour oblique hauls made with the $2 \mathrm{~m}$. stramin ring-trawl, at the Eddystone in March I953 indicated a sparse plankton characterized by Sagitta setosa. In April the hauls both at the Eddystone and EI (Io miles S.S.W. of the Eddystone) were again small in quantity with only very few Sagitta, both $S$. setosa and S. elegans being 
seen. But on II May, at EI, when water for our last experiment was collected, the presence in the continuing sparse plankton of 20 Aglantha rosea showed an influx of western water, although no Sagitta or other indicator species were present. Silicate analyses made by F.A.J.A. also suggest a change in the water mass at E I by II May. This change is paralleled by our results, in so far as such differences as were apparent between larvae reared in waters from EI and the Clyde were more pronounced in the earlier experiments than in the later.

It was unfortunate that the unsuspected copper in the active carbon used in 1952 gave rise to a misleading result. The sea water passed through that particular sample of carbon must have picked up sufficient copper to have become poisonous to the larvae. The larvae in this year's carbon-treated sea water were similar to those in the untreated controls, but the carbon extracts once again proved poisonous to the developing eggs. These results seem to close what had seemed to be an encouraging approach to the solution of the problem through the use of activated carbon.

The attempts to filter the water free from bacteria at the time of collection were mainly unsuccessful but one quantity of $\mathrm{E}$ I water proved to be bacteriafree when examined just before use. The results with it did not differ in any way from those obtained with the water collected at the same time and merely strained into a carboy. Since the bacterial content of this carboy water was high when tested this result is of interest. It is noteworthy, too, that bacteriostatic concentrations of penicillin and streptomycin were without effect.

The addition of various substances, notably the vitamin $\mathrm{B}_{12}$ and the sequestering agent E.D.T.A., did not improve either of the waters: if anything they adversely affected the larvae. Heating the waters generally made them, especially the EI water, worse as a medium for larval development. In artificial sea water the larvae did moderately well, though not quite as well as in the natural sea waters. It may be possible to use artificial sea water as a standard medium with which to compare natural waters and to which to add any substance the effect of which on the larvae it is desired to test.

\section{SUMMARY}

In all comparative tests made in 1953 developing Echinus larvae did only slightly better in sea water from the Clyde than in sea water from the English Channel at Er.

The activated carbon used in one of the 1952 experiments contained a significant amount of copper. The experiment was therefore repeated in I953 with copper-free carbon, and this time the sea water passed through the carbon was not toxic although the carbon extracts were so, as previously found.

Larvae reared in a quantity of $\mathrm{E}_{\mathrm{I}}$ water which had been filtered free from bacteria at the time of collection were no different from larvae reared in water collected at the same time in the usual way. 
Antibiotics in bacteriostatic concentration had no effect on the waters as media for Echinus development.

The addition to the water of extracts of gonads and of filtered coelomic fluid from adult Echinus were detrimental to the larvae, as was also filtered sea water in which other larvae had died and decayed.

Additions of the vitamin $\mathrm{B}_{12}$ and of the sequestering agent E.D.T.A. had little effect on the larvae, being slightly detrimental.

Heating the waters for shorter or longer periods generally had an adverse effect on larvae reared in them.

Larvae reared in artificial sea water, with or without the addition of iron, were in general inferior to those reared in natural sea waters.

\section{REFERENCES}

Lyman, J. \& Fleming, R. H., 1940. Composition of sea water. F. Mar. Res., Vol. 3, pp. $134-46$.

NeEdham, J., I931. Chemical Embryology, Vol. 3. Cambridge.

SPENCER, C. P., I952. On the use of antibiotics for isolating bacteria-free cultures of marine phytoplankton organisms. F. Mar. biol. Ass. U.K., Vol. 3I, pp. 97-IO6.

TYleR, A., I953. Prolongation of life-span of sea urchin spermatozoa, and improvement of the fertilization-reaction, by treatment of spermatozoa and eggs with metal-chelating agents (amino acids, versene, DEDTC, oxine, cupron). Biol. Bull., Wood's Hole, Vol. 104, pp. 224-39.

WILson, D. P., I95I. A biological difference between natural sea waters. F. Mar. biol. Ass. U.K., Vol. 30, pp. I-26.

Wilson, D. P. \& ARmstrong, F. A. J., 1952. Further experiments on biological differences between natural sea waters. F. Mar. biol. Ass. U.K., Vol. 3I, pp. $335-49$. 